\title{
Compressional and shear wave velocities of serpentinized peridotites up to $200 \mathrm{MPa}$
}

\author{
Tohru Watanabe, Hiroaki Kasami, and Shohei Ohshima \\ Department of Earth Sciences, University of Toyama, Gofuku 3190, Toyama 930-8555, Japan
}

(Received April 24, 2006; Revised September 4, 2006; Accepted December 6, 2006; Online published May 7, 2007)

\begin{abstract}
Compressional and shear wave velocities of serpentinized peridotites were measured at room temperature and high confining pressures of up to $200 \mathrm{MPa}$. Rock samples were collected from the Hida outer belt, Central Japan, and classified into High-T (containing antigorite) and Low-T (containing lizardite and/or chrysotile) types. Antigorite is stable up to $600 \sim 700^{\circ} \mathrm{C}$, while lizardite and chrysotile are stable below $300^{\circ} \mathrm{C}$. High-T type samples have distinctly higher velocities than their Low-T type counterparts with the same density. The High-T type with strong foliation shows significant velocity anisotropy, and the azimuthal anisotropy of the compressional wave velocity reaches $30 \%$. These properties can be explained by the crystallographic structure of antigorite. Poisson's ratio increases with serpentinization in both types. The High-T type shows a lower Poisson's ratio than the Low-T type with the same density. The High-T type requires a higher degree of serpentinization than the Low-T type to give a certain value of Poisson's ratio. Observations of high Poisson's ratio have been interpreted using Low-T type properties. However, High-T type serpentinized peridotite is expected in warm subduction zones. The use of Low-T type properties will lead to a significant underestimation of serpentinization. For good interpretations, it is essential to use the properties of the appropriate type of serpentinized peridotite.
\end{abstract}

Key words: Seismic velocity, serpentinized peridotite, antigorite, Poisson's ratio.

\section{Introduction}

Serpentinized peridotites at the slab-mantle interface play important roles in subduction zone processes. They are formed through the hydration of mantle peridotites by aqueous fluids expelled from the subducting slab (e.g., Peacock and Hyndman, 1999). Serpentinized peridotites bring $\mathrm{H}_{2} \mathrm{O}$ to the deeper parts and then break down to release fluid. The released fluid ascends through the wedge mantle and drops the solidus temperature to trigger partial melting (e.g., Iwamori, 1998). This is a key process of arc magmatism. Because of their slippery nature, serpentinized peridotites at the slab-mantle interface can suppress the seismic slip and control the downdip limit of thrust earthquakes (Peacock and Hyndman, 1999). Geophysical imaging of serpentinized peridotites, therefore, can provide clues to an understanding of subduction zone processes.

It is held that the seismic tomography detects the serpentinized wedge mantle in some subduction zones: the Central Japan (Kamiya and Kobayashi, 2000), the Central Andes of South America (Graeber and Asch, 1999), the Cascadea of North America (Bostock et al., 2000), and Costa Rica (DeShon and Schwartz, 2004). The identification of serpentinized peridotites has been based on the seismological observation of low velocities and high Poisson's ratio (e.g., Kamiya and Kobayashi, 2000). Based on a compilation of rock properties, Christensen (1996) suggested that serpentinites be distinguished from other rocks by their anoma-

Copyright (c) The Society of Geomagnetism and Earth, Planetary and Space Sciences (SGEPSS); The Seismological Society of Japan; The Volcanological Society of Japan; The Geodetic Society of Japan; The Japanese Society for Planetary Sciences; TERRAPUB. lously high Poisson's ratio. However, it is questionable whether the argument of Christensen (1996) is applicable to seismic velocities in the wedge mantle.

There are three major forms of serpentine: lizardite, chrysotile, and antigorite (Fig. 1). All three forms have an approximate composition of $\mathrm{Mg}_{3} \mathrm{Si}_{2} \mathrm{O}_{5}(\mathrm{OH})_{4}$. Serpentine minerals are hydrous phyllosilicates composed of a 1:1 layer that is formed by linking one silicon-occupied tetrahedral sheet (Fig. 1(a)) with one magnesium-occupied octahedral sheet (Fig. 1(b)). The lateral dimensions of an ideal magnesium-occupied octahedral sheet $\left(b \sim 9.4 \times 10^{-10} \mathrm{~m}\right)$ are larger than those of an ideal silicon-occupied tetrahedral sheet $\left(b \sim 9.1 \times 10^{-10} \mathrm{~m}\right)$. This misfit between sheets leads to the three serpentine structures, each with a different solution to the misfit problem (Wicks and O'Hanley, 1988). In lizardite, the misfit is accommodated within the normal, planar 1:1 layer structure (Fig. 1(c)); in chrysotile, the misfit is partly overcome by the cylindrical or spiral curvature of the layers (Fig. 1(d)); in antigorite, the misfit is overcome by the curvature of the alternating wave modulation (Fig. 1(e)). The 1:1 layers are bonded by hydrogen bonds in lizardite, while by $\mathrm{Si}-\mathrm{O}$ bonds in antigorite. Consequently, a higher elastic stiffness is expected in antigorite than lizardite. Chrysotile is considered to be more compliant that lizardite due to its lack of interlayer bonding.

Phase relations related to serpentine minerals in the MSH $\left(\mathrm{MgO}-\mathrm{SiO}_{2}-\mathrm{H}_{2} \mathrm{O}\right)$ system are shown in Fig. 2(a) for a pressure below 1.0 GPa. The water pressure is assumed to be equal to the total pressure. From thermodynamical considerations, Sanford (1981) constructed reaction curves of:

$$
\text { chrysotile }=\text { antigorite }+ \text { brucite }\left(\mathrm{Mg}(\mathrm{OH})_{2}\right)
$$


(a) Tetrahedral sheet

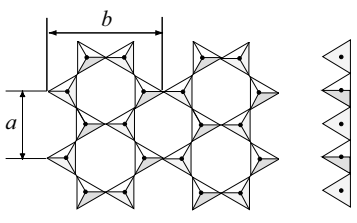

A.V.V.V.V.A.

- : tetrahedral cation $\left(\mathrm{Si}^{4+}\right)$ (b) Tri-octahedral sheet

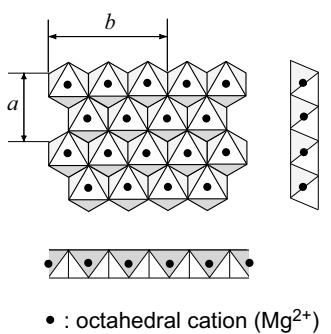

(c) Lizardite

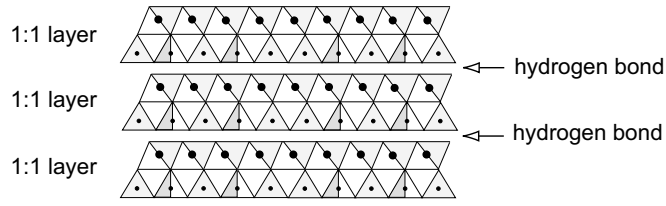

(d) Chrysotile

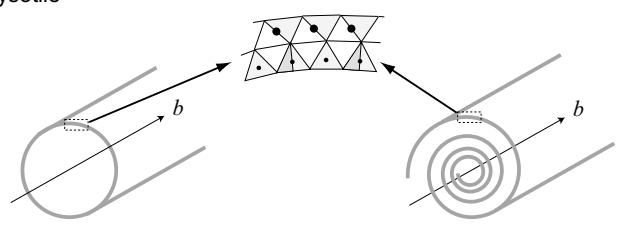

(e) Antigorite

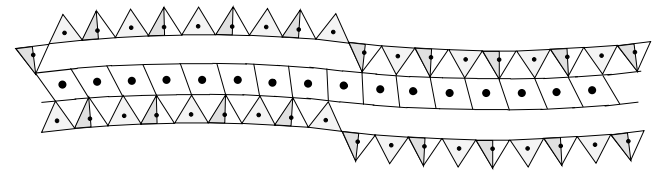

Fig. 1. Structure of serpentines and their fundamental components. (a) $\mathrm{SiO}_{4}$ tetrahedral sheet in plan. The views along the $a$ and $b$ crystallographic axes are also shown. (b) Magnesium-occupied tri-octahedral sheet in plan. The views along the $a$ and $b$ crystallographic axes are also shown. (c) Structure of lizardite viewed along the $b$ crystallographic axis. (d) Structure of chrysotile with 1:1 layer curved cylindrically or spirally around the $b$ crystallographic axis. (e) Structure of antigorite viewed along the $b$ crystallographic axis.

antigorite + brucite $=$ forsterite $\left(\mathrm{Mg}_{2} \mathrm{SiO}_{4}\right)+\mathrm{H}_{2} \mathrm{O}$

chrysotile + brucite $=$ forsterite $+\mathrm{H}_{2} \mathrm{O}$ (A in Fig. 2(a))

chrysotile $=$ antigorite + forsterite $+\mathrm{H}_{2} \mathrm{O}$ (B in Fig. 2(a))

Evans et al. (1976) determined the reaction curve of

$$
\text { antigorite }=\text { forsterite }+ \text { talc }\left(\mathrm{Mg}_{6} \mathrm{Si}_{8} \mathrm{O}_{20}(\mathrm{OH})_{4}\right)+\mathrm{H}_{2} \mathrm{O}
$$

from experimental data. However, there are insufficient data for lizardite to calculate equilibriums in which it is involved. O'Hanley (1987) qualitatively depicted the reaction curve of

$$
\text { lizardite }=\text { chrysotile }
$$

Lizardite is considered to be stable below the reaction of

$$
\text { chrysotile }=\text { antigorite }+ \text { brucite }
$$

on the basis of topologic constraints. Antigorite is stable up to $622^{\circ} \mathrm{C}$ at $1.0 \mathrm{GPa}$ (Evans et al., 1976), while lizardite and chrysotile are stable below $300^{\circ} \mathrm{C}$ (O'Hanley, 1996).

(a)

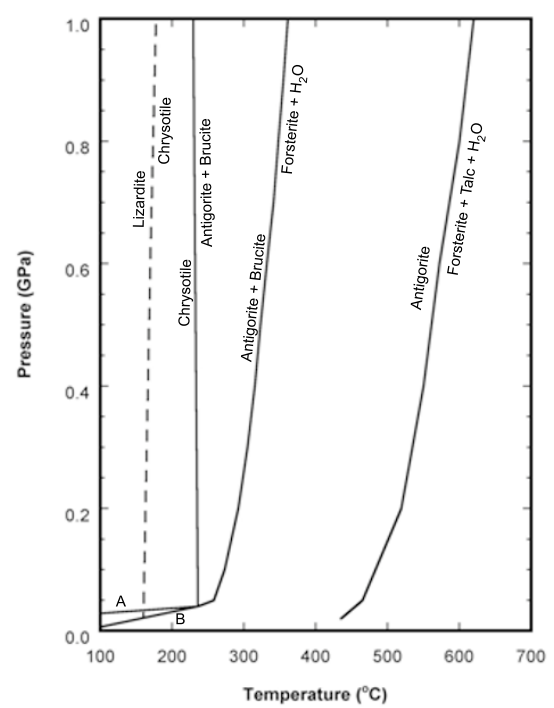

(b)

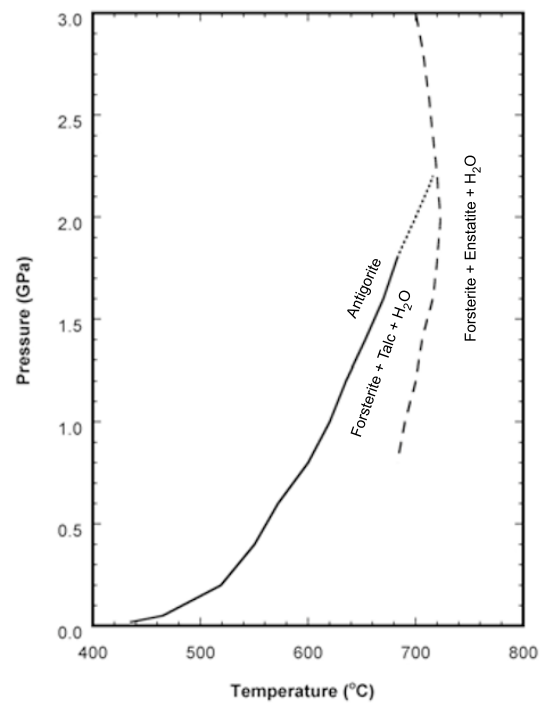

Fig. 2. PT relations related to serpentine minerals in the system MSH ( $\left.\mathrm{MgO}-\mathrm{SiO}_{2}-\mathrm{H}_{2} \mathrm{O}\right)$ system. (a) PT relations below the pressure of $1.0 \mathrm{GPa}$. The water pressure is assumed to be equal to the total pressure. The reaction curves of chrysotile $=$ antigorite + brucite, antigorite + brucite $=$ forsterite $+\mathrm{H}_{2} \mathrm{O}$, A and B were constructed by Sanford (1981). A and B are reaction curves of chrysotile + brucite $=$ forsterite $+\mathrm{H}_{2} \mathrm{O}$ and chrysotile $=$ antigorite + forsterite $+\mathrm{H}_{2} \mathrm{O}$, where the left hand side represents higher pressure phases. The reaction curve of antigorite $=$ forsterite + talc $+\mathrm{H}_{2} \mathrm{O}$ was determined by Evans et al. (1976). The location of the reaction curve of lizardite $=$ chrysotile is constrained qualitatively (O'Hanley, 1987). (b) PT relations related to antigorite up to the pressure of $3.0 \mathrm{GPa}$. The reaction curve of antigorite $=$ forsterite + talc $+\mathrm{H}_{2} \mathrm{O}$ was constrained by Evans et al. (1976) up to $1.8 \mathrm{GPa}$ (solid line), and by Ulmer and Trommsdorff (1995) at higher temperatures (dotted line). The reaction curves of forsterite + talc $+\mathrm{H}_{2} \mathrm{O}=$ forsterite + enstatite $+\mathrm{H}_{2} \mathrm{O}$ and antigorite $=$ forsterite + enstatite $+\mathrm{H}_{2} \mathrm{O}$ (broken line) were constrained by Ulmer and Trommsdorff (1995).

Hereafter, we call chrysotile and lizardite Low-T type serpentines, and antigorite a High-T type serpentine.

The stability field of antigorite in the MSH system is shown in Fig. 2(b) for pressures up to 3.0 GPa. The high temperature limit of the stability field has a maximum tem- 
Table 1. Petrography, density, serpentine content and locality of rock samples.

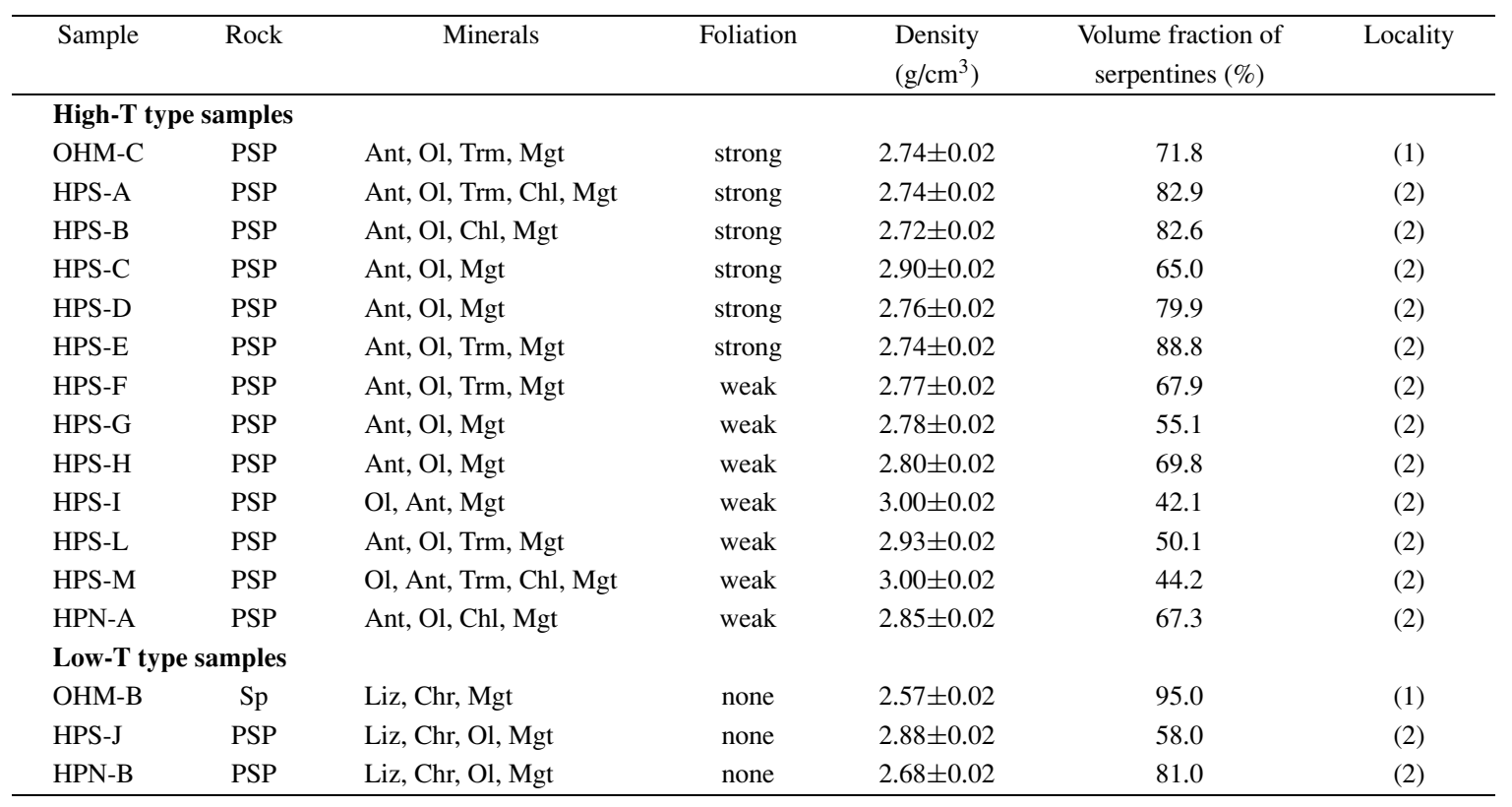

Minerals are arranged in order of volume.

Abbreviations are PSP, partially serpentinized peridotite; Sp, serpentinite; Ant, antigorite; Ol, olivine; Trm, tremolite; Mgt, magnetite; Chl, chlorite; Liz, lizardite; Chr, chrysotile.

(1) Ohmi, Niigata Pref., Japan, (2) Hakuba, Nagano Pref., Japan

perature of $700^{\circ} \mathrm{C}$ at $2.2 \mathrm{GPa}$, and then decreases with increasing pressure (Ulmer and Trommsdorff, 1995).

Christensen (1996) calculated average velocities and Poisson's ratios from measured velocity data of serpentinites (e.g., Christensen, 1966). Although Christensen (1978) measured a high velocity in one antigorite-bearing serpentinized peridotite, most of his samples contain lizardite and/or chrysotile (Christensen, 1966, 1972, 1978). The average velocities calculated by Christensen (1996) are thus appropriate only for Low-T type serpentinized peridotites (containing lizardite and/or chrysotile). Numerical studies have shown that the temperature at the slab-mantle interface is higher than $300^{\circ} \mathrm{C}$ in warm subduction zones (e.g., Peacock and Wang, 1999). The seismic properties of High-T type serpentinized peridotites (containing antigorite) are therefore essential to any interpretation of seismological observations. A few studies have reported elastic wave velocities of High-T type serpentinized peridotites (Birch, 1960; Christensen, 1978; Kern et al., 1997). However, in each of these studies the measurement was based on only one or two samples and, to date, there has been no systematic study on the velocities of High-T type serpentinized peridotites.

We report here our measurements of compressional and shear wave velocities in High-T and Low-T type serpentinized peridotites. Rock samples range from moderately to completely serpentinized peridotites, and they show a wide variety of petrofabric. The velocity measurements were conducted at room temperature under high confining pressures of up to $200 \mathrm{MPa}$. We show that High-T type serpentinized peridotites have significantly different properties from Low-T types, and we discuss the applications of serpentinized peridotites to seismological observations.

\section{Measurements \\ 2.1 Rock samples}

Rock samples were collected from the Hida outer belt, Central Japan. There are many outcrops of serpentinized peridotites associated with High-P/Low-T metamorphic rocks (blueschist eclogite facies) in this region (Chihara et al., 1979). A description of the studied samples is presented in Table 1. When olivine is identified in a rock sample, the sample is described as partially serpentinized peridotite (PSP in Table 1). A rock composed mainly of serpentines without olivine is described as serpentinite (Sp in Table 1). Olivine grains should have been completely altered. Sample OHM-B is a serpentinite mostly composed of lizardite and chrysotile. Minerals are arranged in order of volume in Table 1 . The density was calculated from the volume and mass was measured at atmospheric pressure. The volume fraction of serpentines was estimated by the point counting method: 2500-3000 points were counted over an area of $126 \mathrm{~mm}^{2}$ for each rock. Although relatively large scattering is seen, the density decreases with the increase in the serpentine volume fraction.

Serpentine minerals were identified by the powder X-ray diffraction technique and petrographical observation. Examples of X-ray diffraction spectra are shown in Fig. 3. The normalized intensity is shown as a function of $2 \theta$, where $\theta$ is the incident angle of the X-ray (wavelength $=1.54050 \AA$ ). Because the three serpentine minerals show a high degree of structural similarity, most of the peak positions are quite close together. However, lizardite and chrysotile have peaks around $20^{\circ}$, which distinguishes these types from the other major minerals in the rock samples. We were therefore able to distinguish Low-T types from High-T types by this peak. Lizardite and chrysotile were distinguished on the 


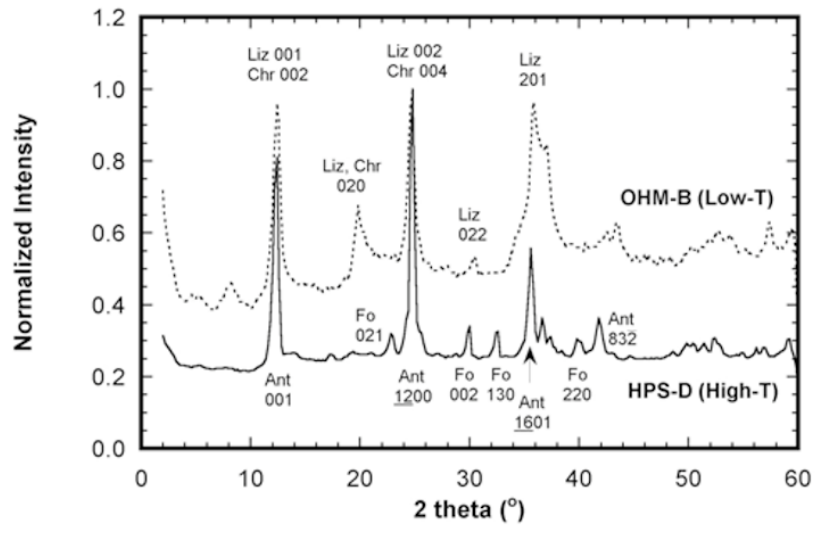

Fig. 3. X-ray diffraction spectra of OHM-B (Low-T type) and HPS-D (High-T type). The intensity is normalized by the observed maximum intensity of a specimen. The wavelength of incident X-ray was 1.54050 $\AA$ (Copper $\left.\mathrm{K}_{\alpha 1}\right)$. Major peaks are indexed. Abbreviations: Ant, antigorite; Liz, lizardite; Chr, chrysotile; Fo, forsterite. Low-T type serpentines are distinguished from High-T type by the peak around $20^{\circ}$.

basis of optical characteristics. Lizardite is length-fast, and chrysotile length-slow (Wicks and O'Hanley, 1988). Length-fast means that the fast ray oscillates more or less parallel to the length of an elongated mineral, while lengthslow means that the slow ray oscillates more or less parallel to the length (Nesse, 2004).
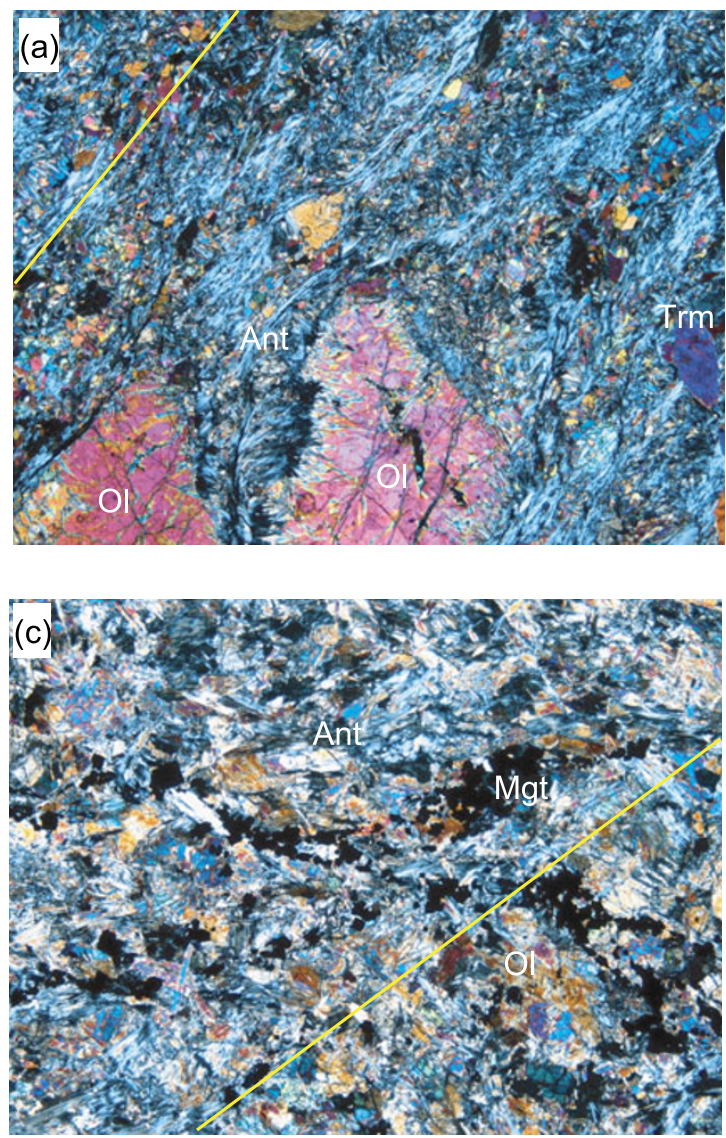
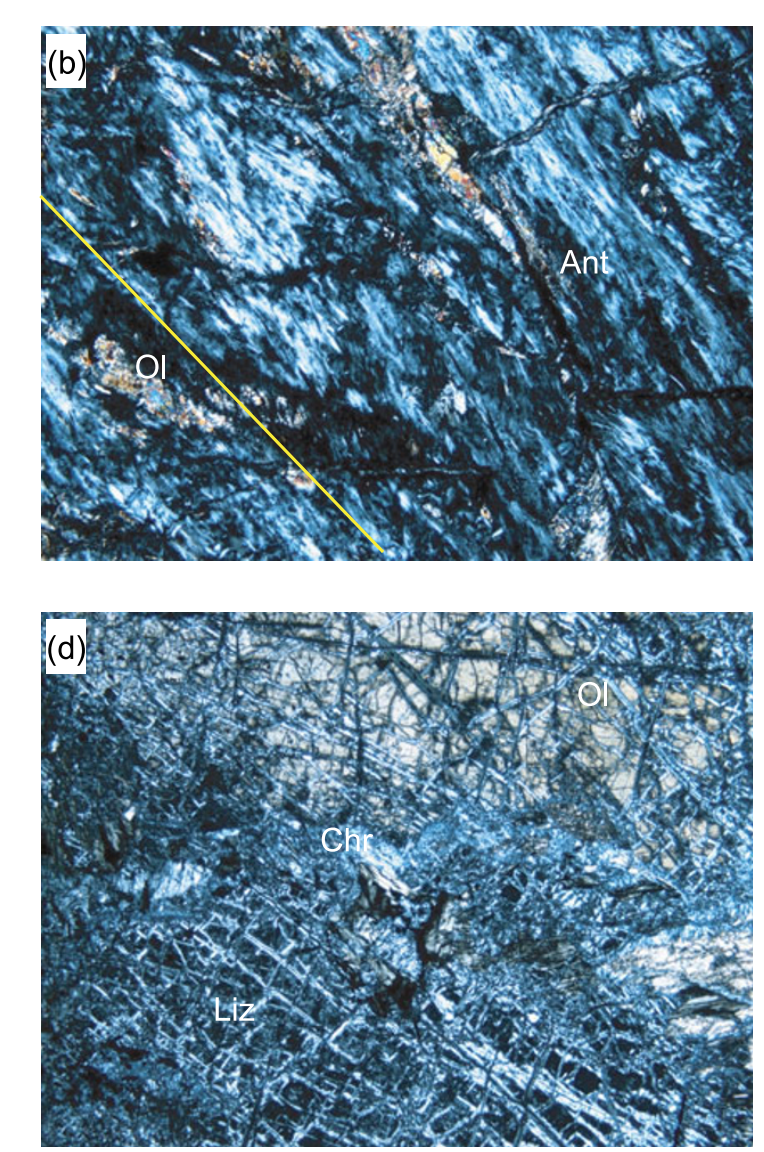

We studied 13 High-T type and three Low-T type samples. It should be noted that some of the collected rocks contain both High-T and Low-T type serpentines. They may have recorded alteration processes of different temperatures. Such rocks were omitted from this study in order to clarify the difference in elastic properties between High-T and Low-T type serpentinized peridotites.

High-T type samples are mainly composed of antigorite and olivine (Fig. 4(a)-(c)). All of these contain magnetite, and some contain tremolite and/or chlorite. Olivine and tremolite must exist in the original peridotite, but chlorite and magnetite are byproducts of serpentinization. Magnetite grains are distributed in former grain boundaries and/or veins. Most of High-T type samples have strong foliation, where antigorite grains are aligned parallel or subparallel to the foliation (Fig. 4(b)). On the other hand, some samples have weak foliation (Fig. 4(c)).

Low-T type samples are mainly composed of lizardite and chrysotile (Fig. 4(d)). Olivine is also present in HPS-J and HPN-B (Fig. 4(d)). Magnetite grains are distributed in former grain boundaries and/or veins. Low-T type samples show no foliation.

A cube (the edge length $\sim 30 \mathrm{~mm}$ ) was cut from each rock sample for velocity measurements. When a rock showed remarkable foliation, a cube was cut so that two faces were parallel to the foliation plane. The other four faces were perpendicular to the foliation plane: two were parallel to the

Fig. 4. Photomicrographs (crossed-polars) of rock samples. The width is $6 \mathrm{~mm}$. A yellow line indicates the orientation parallel to foliation planes. (a) Olivine grains $(\mathrm{Ol}$ ) are partially replaced by antigorite (Ant) grains (HPS-M). (b) Antigorite grains are aligned parallel or subparallel to the foliation plane in a sample with strong foliation (HPS-D). (c) Antigorite grains are almost ramdomly oriented in a sample with weak foliation (HPS-G). (e) Lizardite mesh-rim texture (HPN-B). 
Table 2. Compressional wave velocities and azimuthal anisotropy.

\begin{tabular}{|c|c|c|c|c|c|}
\hline Sample & $\begin{array}{l}V p(\mathrm{x}) \\
(\mathrm{km} / \mathrm{s})\end{array}$ & $\begin{array}{l}V p(\mathrm{y}) \\
(\mathrm{km} / \mathrm{s})\end{array}$ & $\begin{array}{l}V p(\mathrm{z}) \\
(\mathrm{km} / \mathrm{s})\end{array}$ & $\begin{array}{l}V p^{\text {mean }} \\
(\mathrm{km} / \mathrm{s})\end{array}$ & $k_{p}$ \\
\hline \multicolumn{6}{|c|}{ High-T type samples } \\
\hline OHM-C & $7.33 \pm 0.09$ & $6.91 \pm 0.08$ & $5.73 \pm 0.06$ & 6.66 & $(2.40 \pm 0.05) \times 10^{-1}$ \\
\hline HPS-A & $7.60 \pm 0.10$ & $7.39 \pm 0.09$ & $6.18 \pm 0.07$ & 7.06 & $(2.01 \pm 0.05) \times 10^{-1}$ \\
\hline HPS-B & $7.36 \pm 0.09$ & $6.33 \pm 0.07$ & $6.21 \pm 0.07$ & 6.63 & $(1.74 \pm 0.03) \times 10^{-1}$ \\
\hline HPS-C & $7.43 \pm 0.10$ & $6.81 \pm 0.08$ & $6.74 \pm 0.08$ & 6.99 & $(9.9 \pm 0.2) \times 10^{-2}$ \\
\hline HPS-D & $7.57 \pm 0.10$ & $6.61 \pm 0.08$ & $5.80 \pm 0.06$ & 6.66 & $(2.67 \pm 0.05) \times 10^{-1}$ \\
\hline HPS-E & $7.06 \pm 0.09$ & $6.99 \pm 0.08$ & $5.85 \pm 0.06$ & 6.63 & $(1.83 \pm 0.04) \times 10^{-1}$ \\
\hline HPS-F & $7.00 \pm 0.08$ & $6.98 \pm 0.08$ & $6.29 \pm 0.07$ & 6.76 & $(1.05 \pm 0.02) \times 10^{-1}$ \\
\hline HPS-G & $6.52 \pm 0.07$ & $6.46 \pm 0.07$ & $6.48 \pm 0.07$ & 6.49 & $(9.0 \pm 0.2) \times 10^{-2}$ \\
\hline HPS-H & $7.49 \pm 0.10$ & $6.64 \pm 0.08$ & $6.41 \pm 0.07$ & 6.85 & $(1.58 \pm 0.03) \times 10^{-1}$ \\
\hline HPS-I & $7.60 \pm 0.10$ & $7.25 \pm 0.09$ & $7.06 \pm 0.09$ & 7.30 & $(7.3 \pm 0.2) \times 10^{-2}$ \\
\hline HPS-L & $7.66 \pm 0.10$ & $6.85 \pm 0.08$ & $6.60 \pm 0.08$ & 7.04 & $(1.51 \pm 0.03) \times 10^{-1}$ \\
\hline HPS-M & $7.55 \pm 0.10$ & $7.13 \pm 0.09$ & $6.72 \pm 0.08$ & 7.13 & $(1.16 \pm 0.02) \times 10^{-1}$ \\
\hline HPN-A & $7.21 \pm 0.09$ & $6.46 \pm 0.07$ & $6.33 \pm 0.07$ & 6.67 & $(1.32 \pm 0.03) \times 10^{-1}$ \\
\hline \multicolumn{6}{|c|}{ Low-T type samples } \\
\hline OHМ-B & $5.05 \pm 0.05$ & $5.02 \pm 0.05$ & $5.01 \pm 0.05$ & 5.03 & $(8.0 \pm 0.1) \times 10^{-3}$ \\
\hline HPS-J & $6.48 \pm 0.07$ & $6.29 \pm 0.07$ & $6.21 \pm 0.07$ & 6.33 & $(4.3 \pm 0.1) \times 10^{-2}$ \\
\hline HPN-B & $5.92 \pm 0.06$ & $5.77 \pm 0.06$ & $5.67 \pm 0.06$ & 5.79 & $(4.4 \pm 0.1) \times 10^{-2}$ \\
\hline
\end{tabular}

lineation in the foliation plane, and the remaining two were perpendicular to the lineation. The orthogonal axes were determined for velocity measurements. The $z$-axis was set to be perpendicular to the foliation plane, the $x$-axis was set to be parallel to the lineation and the $y$-axis perpendicular to that. When a laminar structure could not be seen in a rock, a cube was cut arbitrarily, and the axes were determined after the velocity measurements. The $x$-axis was set to be the fastest direction of the compressional wave, and the $z$-axis the slowest direction.

\subsection{Procedures}

Both compressional and shear wave velocities were measured by the pulse transmission technique using $\mathrm{Pb}(\mathrm{Zr}$, Ti) $\mathrm{O}_{3}$ transducers with resonant frequency of $2 \mathrm{MHz}$. The elastic wave was excited by a function generator (Hewlett Packard, 33120A), and the received signal was digitized and averaged over 512 times by a digital oscilloscope (Agilent Technologies, 54621A). The sampling interval was 5 nsec. The digitized signal of 12-bit resolution was transferred to a computer for analysis.

A hydrostatic pressure of up to $200 \mathrm{MPa}$ was applied to the specimens. A cube specimen with glued transducers was covered with silicone rubber and loaded into a pressure vessel. Silicone oil (Shin-Etsu Chemical, KF-96-100cs) was used as a pressure medium. All of the measurements were conducted at room temperature. One compressional wave velocity and two shear wave velocities were measured in each of three orthogonal directions. Two shear waves propagating in the same direction oscillate in mutually perpendicular directions. The number of electrical feedthroughs limited the number of velocities measurable during one loading cycle; consequently, three loading cycles were needed for a specimen. The compressional wave velocities were measured during the first loading, and the shear wave velocities were measured during the second and

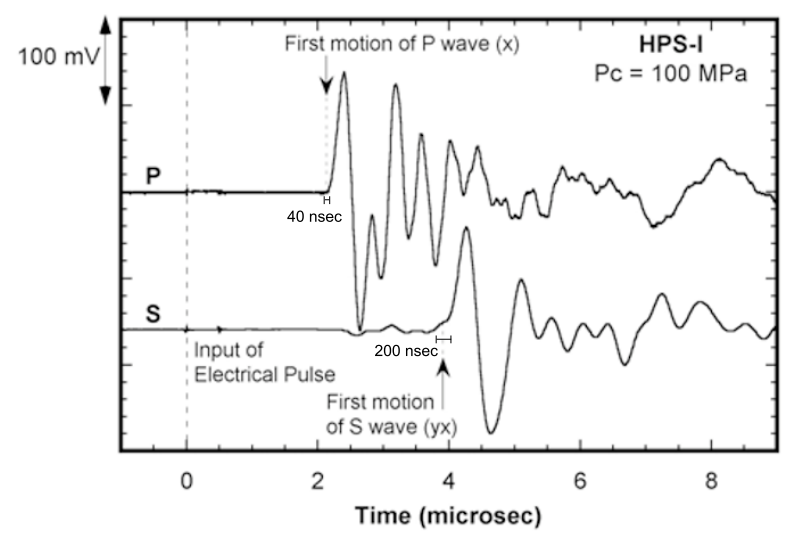

Fig. 5. Examples of waveform data. The compressional and shear waves traveled in the direction of the $x$-axis in HPS-I (High-T type serpentinized peritotite) under $100 \mathrm{MPa}$. The shear wave oscillates in the direction of the $y$-axis. The first motion of the compressional wave can be clearly seen, while that of the shear wave is obscured by the preceding compressional wave that is converted from the transmitted shear wave.

third loadings.

The error in a measured velocity originates in errors in the travel time and path length as

$$
\left|\frac{\delta v}{v}\right| \leq\left|\frac{\delta t}{t}\right|+\left|\frac{\delta l}{l}\right|
$$

where $v, t$ and $l$ are the velocity, travel time, and path length, respectively. The errors in these values are denoted by $\delta v, \delta t$, and $\delta l$, respectively. The error in a travel time depends on the quality of waveform data. Typical waveform data are shown in Fig. 5. The compressional and shear waves traveled the identical path. The uncertainty in reading the first motion is $20 \mathrm{nsec}$ for the compressional wave. The first motion of the shear wave is obscured by the pre- 
(a) HPS-D, Compressional Wave

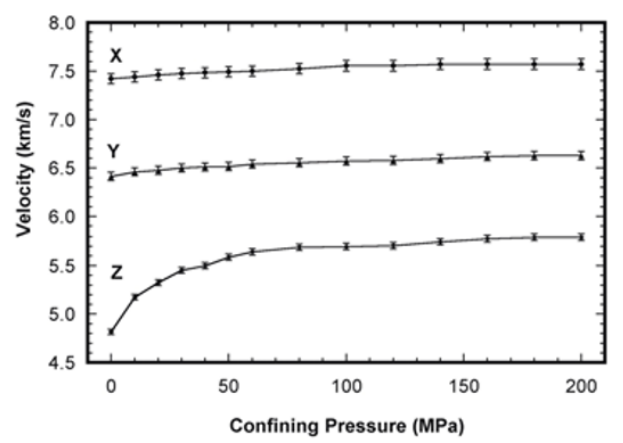

(c) HPS-D, Shear Wave
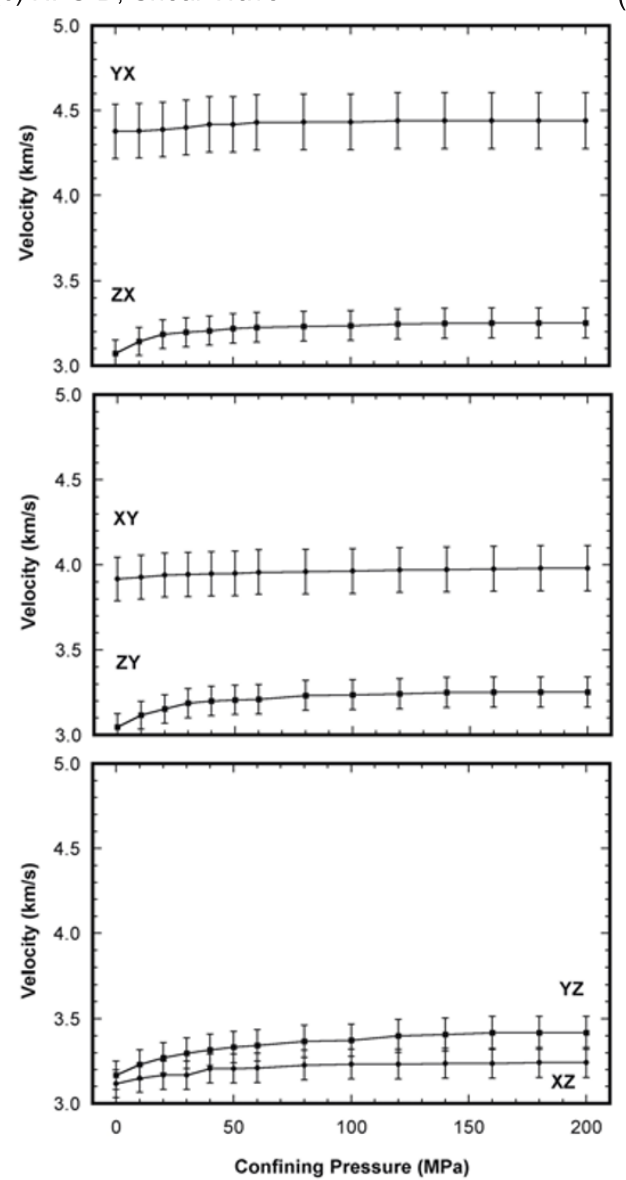

(b) HPS-I, Compressional Wave

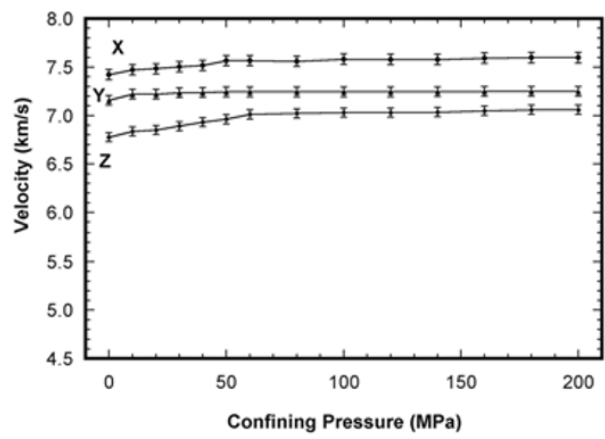

(d) HPS-I, Shear Wave
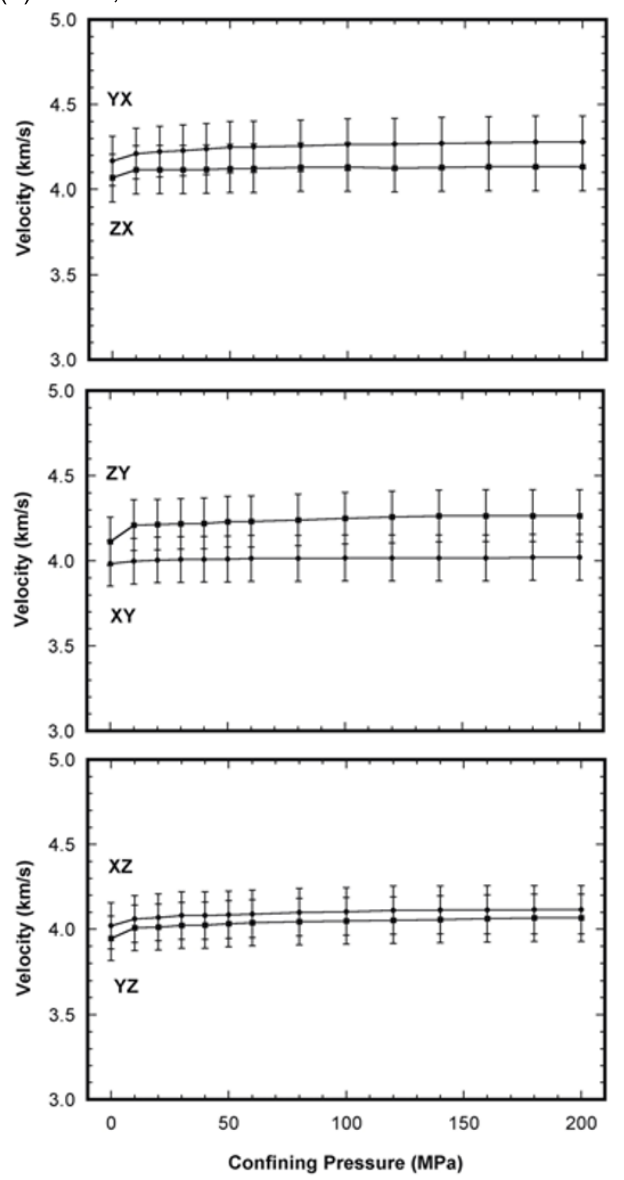

Fig. 6. Typical velocity changes with the confining pressure. The compressional wave velocities in HPS-D (a) and HPS-I (b); the shear wave velocities in HPS-D (c) and HPS-I (d). Velocities were measured with increasing confining pressure. The compressional wave velocity was measured during the first loading, and the shear wave velocity the second and third loading.

ceding compressional wave that must be converted from the transmitted shear wave somewhere between transducers. The uncertainty in the arrival time is $100 \mathrm{nsec}$ for the shear wave. In our measurements, the error was 20-30 nsec for the compressional wave, and 100-150 nsec for the shear wave. Since the travel time is typically 2 and $4 \mu \mathrm{sec}$ for the compressional and shear waves, the magnitude of the first term in Eq. (1) is around 0.01 and 0.03 , respectively.

The error in the path length originates in the measurement error and the contraction under confining pressures. The length measurement involves an error of the order of $0.05 \mathrm{~mm}$. We estimate the dimensional change of a rock specimen by assuming isotropic elasticity. The compressibility can be estimated to be around $1 \times 10^{-11} \mathrm{~Pa}^{-1}$ from the elastic wave velocities and density. The dimensional change is thus of the order of $0.02 \mathrm{~mm}$ at the confining pressure of $200 \mathrm{MPa}$. The error in the path length can therefore be estimated to be less than $0.07 \mathrm{~mm}$. Since the path length is around $30 \mathrm{~mm}$, the magnitude of the second term in (1) is less than 0.003 . The error in the velocity therefore primarily originates in the error in the travel time.

\section{Results}

\subsection{Velocity change with confining pressure}

Velocities of compressional and shear waves increase with increasing confining pressure. Typical velocity changes are shown for a sample with strong foliation (Fig. 6(a) and (c)) and a sample with weak foliation 
Table 3. Shear wave velocities and polarization anisotropies.

\begin{tabular}{|c|c|c|c|c|c|c|c|c|c|c|}
\hline San & $\begin{array}{c}V s(y x) \\
(\mathrm{km} / \mathrm{s})\end{array}$ & $\begin{array}{l}V s(z x) \\
(\mathrm{km} / \mathrm{s})\end{array}$ & $A x$ & $\begin{array}{l}V s(z y) \\
(\mathrm{km} / \mathrm{s})\end{array}$ & $\begin{array}{c}V s(x y) \\
(\mathrm{km} / \mathrm{s})\end{array}$ & $A y$ & $\begin{array}{l}V s(x z) \\
(\mathrm{km} / \mathrm{s})\end{array}$ & $\begin{array}{l}V s(y z) \\
(\mathrm{km} / \mathrm{s})\end{array}$ & $A z$ & $\begin{array}{l}V s^{\text {mean }} \\
(\mathrm{km} / \mathrm{s})\end{array}$ \\
\hline \multicolumn{11}{|c|}{ High-T type samples } \\
\hline OHM-C & $3.85 \pm 0.10$ & 3 & & $3.29 \pm 0.07$ & $3 \pm 0.11$ & $(2.3 \pm 0.1) \times 10^{-1}$ & $3.23 \pm 0.07$ & $3.46 \pm 0.08$ & $(0.9 \pm 0.2) \times 10$ & 3.52 \\
\hline HPS-A & $4.04 \pm 0.11$ & $81 \pm 0.10$ & $9 \pm 0.2) \times 10^{-2}$ & $3.23 \pm 0.07$ & $4.20 \pm 0.12$ & $(2.6 \pm 0.1) \times 10^{-1}$ & $3.35 \pm 0.08$ & $2.85 \pm 0.05$ & $(1.61 \pm 0.05) \times 10^{-1}$ & 3.58 \\
\hline HPS-B & $4.06 \pm 0.11$ & $3.80 \pm 0.10$ & $(6.6 \pm 0.2) \times 10^{-2}$ & $3.46 \pm 0.08$ & $3.97 \pm 0.11$ & $(1.4 \pm 0.1) \times 10^{-1}$ & $3.69 \pm 0.09$ & $3.55 \pm 0.08$ & $(3.9 \pm 0.1) \times 10^{-2}$ & 3.76 \\
\hline HPS-C & $3.84 \pm 0.10$ & $4.16 \pm 0.12$ & $(8.0 \pm 0.3) \times 10^{-2}$ & $3.95 \pm 0$ & $3.93 \pm 0$ & $(5.0 \pm 0.2) \times 10^{-3}$ & $3.90 \pm 0.10$ & $3.88 \pm 0.10$ & $(5.0 \pm 0.1) \times 10^{-3}$ & 3.94 \\
\hline HPS-D & $4.44 \pm 0.13$ & $3.25 \pm 0.07$ & $(3.1 \pm 0.1) \times 10^{-1}$ & $3.25 \pm 0.07$ & $3.98 \pm 0.11$ & $(2.0 \pm 0.1) \times 10^{-1}$ & $3.24 \pm 0.07$ & $3.42 \pm 0.08$ & $(5.2 \pm 0.2) \times 10^{-2}$ & 3.60 \\
\hline HPS-E & $4.28 \pm 0.12$ & $3.51 \pm 0.08$ & $(2.0 \pm 0.1) \times$ & $3.51 \pm 0.08$ & $4.21 \pm 0.12$ & $(1.8 \pm 0.1) \times$ & $3.33 \pm 0$ & $3.45 \pm 0.08$ & & 3.71 \\
\hline HPS-F & $4.04=$ & $3.72 \pm 0.09$ & $(8.2 \pm 0.3)$ & $3.65 \pm 0.09$ & $4.14 \pm 0.12$ & $(1.3 \pm 0.1) \times$ & $3.69 \pm$ & $3.76 \pm$ & & 3.83 \\
\hline HPS-G & $3.81 \pm 0$ & $3.41 \pm 0.08$ & $(1.1 \pm 0.1) \times$ & $3.71 \pm 0.09$ & $3.58 \pm 0.09$ & $(3.6 \pm 0.1)$ & $3.56 \pm$ & 3.75 & & 3.64 \\
\hline HPS-H & $4.26 \pm 0.12$ & $4.21 \pm$ & $(1.2 \pm$ & $3.70 \pm 0.09$ & $4.09 \pm 0.11$ & & $3.83=$ & $3.78 \pm 0$ & & 3.98 \\
\hline HPS-I & $4.28 \pm 0.12$ & $4.13 \pm 0.11$ & $(3.4 \pm 0.1) \times 10^{-2}$ & $4.27 \pm 0.12$ & $4.02 \pm 0.11$ & $(5.9 \pm 0.2) \times 10^{-2}$ & $4.12 \pm$ & $4.07 \pm 0.11$ & & 4.15 \\
\hline HPS-L & $4.10 \pm 0.11$ & $3.97 \pm 0.11$ & $(3.2 \pm 0.1) \times 10^{-2}$ & $3.75 \pm 0.09$ & $4.03 \pm 0.11$ & $(7.2 \pm 0.3) \times 10^{-2}$ & $3.88 \pm 0.10$ & $3.77 \pm 0.10$ & & 3.92 \\
\hline HPS-M & $4.23 \pm 0.12$ & $3.90 \pm 0.10$ & $(8.1 \pm 0.3) \times 10^{-2}$ & $3.97 \pm 0.11$ & $4.36 \pm 0.13$ & $(9.4 \pm 0.4) \times 10^{-2}$ & $4.07 \pm 0.11$ & $4.10 \pm 0.11$ & & 4.11 \\
\hline HPN-A & $3.97 \pm 0.11$ & $3.97 \pm 0.11$ & $0.0 \pm 0.1$ & $3.75 \pm 0.09$ & $3.62 \pm 0.09$ & $(3.5 \pm 0.1) \times 10^{-2}$ & $3.82 \pm 0.10$ & $3.48 \pm 0.08$ & $(9.3 \pm 0.3) \times 10^{-2}$ & 3.77 \\
\hline \multicolumn{11}{|c|}{ Low-T type samples } \\
\hline OHM-B & $2.63 \pm 0.05$ & $2.59 \pm 0.05$ & & $2.61 \pm 0.05$ & & & $2.67 \pm 0.05$ & $2.66 \pm 0.05$ & & 2.62 \\
\hline HPS-J & $3.49 \pm 0.08$ & $3.47 \pm 0.08$ & $(6.0 \pm 0.2) \times 10^{-3}$ & $3.46 \pm 0.08$ & $3.39 \pm 0.08$ & $(2.0 \pm 0.1) \times 10^{-2}$ & $3.33 \pm 0.07$ & $3.15 \pm 0.07$ & $(5.6 \pm 0.2) \times 10^{-2}$ & 3.38 \\
\hline HPN-B & $2.99 \pm 0.06$ & $2.97 \pm 0.06$ & $(7.0 \pm 0.2) \times 10^{-3}$ & $3.07 \pm 0.06$ & $3.08 \pm 0.06$ & $(3.0 \pm 0.1) \times 10^{-3}$ & $2.98 \pm 0.06$ & $3.01 \pm 0.06$ & $(1.0 \pm 0.1) \times 10^{-2}$ & 3.02 \\
\hline
\end{tabular}

$V s(i j)$ is the velocity of a shear wave propagating in the direction of $j$-axis and oscillating in the direction of $i$-axis.

$A_{h}$ is defined by Eq. (3).

$V s^{\text {mean }}$ is the arithmetic mean of six shear wave velocities.

(Fig. 6(b) and (d)). Most of velocity increase was observed below $100 \mathrm{MPa}$, whereas only slight increase at higher pressures. The velocity increase below a few hundred MPa is due to the closure of pores (e.g., Birch, 1960). Compressional and shear wave velocities measured at $200 \mathrm{MPa}$ are summarized in Tables 2 and 3, respectively. $V p(i)$ is the velocity of a compressional wave propagating in the direction of the $i$-axis, and $V s(i j)$ is the velocity of a shear wave propagating in the direction of the $j$-axis and oscillating in the direction of $i$-axis. $V p^{\text {mean }}$ is the arithmetic mean of three compressional wave velocities, and $V s^{\text {mean }}$ is the mean of six shear wave velocities. The influence of pores seems to be sufficiently small at $200 \mathrm{MPa}$.

Samples with strong foliation tend to show large changes in velocity during loading (Fig. 6(a) and (b)). Sample HPSD shows strong foliation, but HPS-I shows weak foliation. In sample HPS-D, the largest increase in the compressional wave velocity was observed in the direction perpendicular to the foliation, suggesting the presence of a large number of cracks parallel to the foliation. Microstructural observation confirmed the existence of cracks parallel or subparallel to the foliation planes.

The increase in shear wave velocities at low pressures is rather small compared to the increase in compressional wave velocities (Fig. 6(c) and (d)). Theoretical studies have shown that the shear wave velocity is less sensitive to the existence of cracks than the compressional wave velocity (e.g., O'Connell and Budiansky, 1974). Our result is consistent with the theoretical prediction. The smaller change in the shear wave velocity can be partly attributed to the closure of pores during the first loading. After the first loading, the compressional wave velocity at atmospheric pressure became higher than the initial value, suggesting that some pores remain closed after unloading. Although the first loading increased shear wave velocities at atmospheric pressure, it barely affected velocities at high pressures.

\subsection{Velocity anisotropy}

The anisotropy of wave velocities generally weakens with increasing confining pressure (Fig. 7). The azimuthal anisotropy of the compressional wave velocity is characterized by the coefficient of anisotropy $k_{p}$ introduced by Birch (1961) as

$$
k_{p}=\frac{V_{\max }-V_{\min }}{V_{\text {mean }}}
$$

where $V_{\max }$ and $V_{\min }$ are the maximum and minimum velocities, respectively, in three mutually perpendicular directions. The arithmetic mean of three velocities is denoted by $V_{\text {mean }}$. The polarization anisotropy of the shear wave velocity is characterized by $A_{h}$, which is defined as

$$
A_{h}=\frac{\left|V s^{i h}-V s^{j h}\right|}{\frac{1}{2}\left(V s^{i h}+V s^{j h}\right)}
$$

where $V s^{i h}$ is the velocity of the shear wave propagating in the direction of $h$ and oscillating in the direction of $i$. The numerator is the velocity difference between two shear waves oscillating in mutually perpendicular directions, while the denominator is the arithmetic mean of two shear wave velocities. Similar to the velocity change, most of the change in anisotropy was observed below $100 \mathrm{MPa}$, suggesting that the anisotropy observed at low pressures can be attributed to the pores. The closure of cracks parallel or subparallel to the foliation can explain both the increase in velocities and the decrease in anisotropy. As an exception, the polarization anisotropy $A z$ of HPS-D increased slightly with increasing confining pressure (Fig. 7(b)). This will be discussed in Section 4.1.

Anisotropy coefficients $k_{p}$ and $A_{h}$ at $200 \mathrm{MPa}$ are summarized in Tables 2 and 3 . Most of samples still show significant velocity anisotropy at $200 \mathrm{MPa}$. Samples with remarkable foliation tend to be highly anisotropic: sample HPS-D has strong foliation and shows an azimuthal 

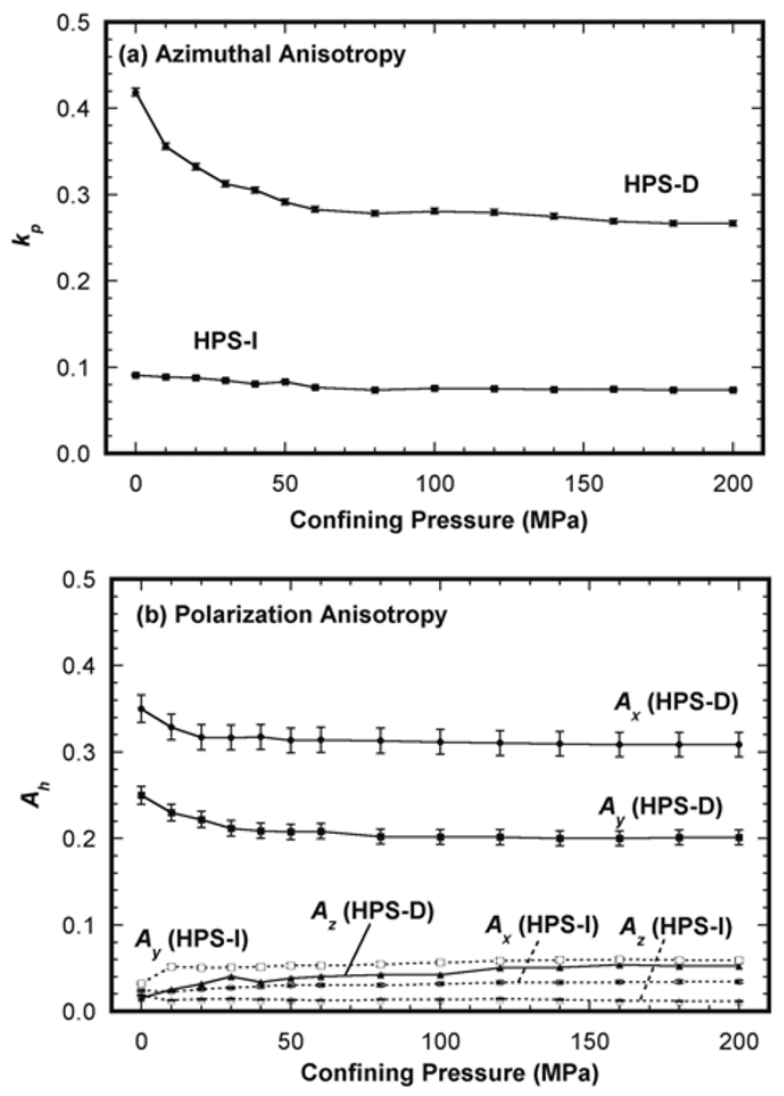

Fig. 7. Velocity anisotropy as a function of the confining pressure. (a) The azimuthal anisotropy of the compressional wave velocity in HPS-D and HPS-I. (b) The polarization anisotropy of the shear wave velocity in HPS-D and HPS-I. Velocities were measured with increasing confining pressure. The compressional wave velocity was measured during the first loading, and the shear wave velocity were measured during the second and third loading.

anisotropy of $27 \%$, whereas sample HPS-I has weak foliation and shows an azimuthal anisotropy of $7 \%$. The lowest compressional wave velocity was observed in the direction perpendicular to the foliation, and the highest velocity occurred parallel to the lineation. Contrary to High-T type serpentinized peridotites, none of Low-T type samples shows significant foliations (Table 1, Fig. 4). The velocity anisotropy is weak in the Low-T type compared to the High-T type (Tables 2 and 3).

\section{Discussion}

\subsection{Cause of velocity anisotropy at high pressures}

The lattice-preferred orientation must be the dominant cause of velocity anisotropy in High-T type samples at 200 $\mathrm{MPa}$. The High-T type samples have more or less remarkable foliation, and most of the platy antigorite grains align parallel or subparallel to the foliation planes (Fig. 4(b)). Kern et al. (1997) reported a similar velocity anisotropy of a serpentinized peridotite involving $75 \mathrm{vol} \%$ antigorite with well-developed foliation. They studied the orientation of antigorite crystals using an X-ray texture goniometer and found that the antigorite c-axes are roughly perpendicular to the foliation plane. This means that the sheet structure of antigorite crystals aligns parallel to the foliation. Although the elastic properties of antigorite single-crystal have not been reported, the crystallographic structure of antigorite suggests that the elastic stiffness is weaker in the direction perpendicular to the sheet structure than in that parallel to the sheet structure. The lattice-preferred orientation of antigorite is thus the primary cause of velocity anisotropy (Kern et al., 1997). This interpretation can be applied to our observed anisotropy. A further understanding of the anisotropy requires the statistics of the orientation of major mineral grains and the investigation on elastic properties of antigorite single crystal.

The alignment of pores and that of elastically anisotropic grains can work simultaneously to cause velocity anisotropy. The effect of pores weakens with increasing confining pressure due to the closure of pores. The dominant cause of anisotropy can change from the alignment of pores to the alignment of grains with increasing confining pressure. If the contributions from pores and anisotropic grains are additive, the magnitude of anisotropy will decrease with increasing confining pressure. However, the polarization anisotropy $A z$ of HPS-D increases with increasing confining pressure (Section 3.2). This observation suggests that the effect of pores at low pressures works to diminish the anisotropy $A z$ due to the alignment of grains in HPS-D.

The weak velocity anisotropy in Low-T type samples at $200 \mathrm{MPa}$ is explained by their petrofabric. Low-T type serpentines (lizardite and chrysotile) should be elastically anisotropic due to their crystallographic structures (Fig. 1). However, Low-T type serpentine fibers orient approximately perpendicular to former grain boundaries and veins, resulting in an almost random orientation of serpentine grains. The other mineral grains show little alignment. The orientation of mineral grains is thus nearly random to suppress velocity anisotropy.

Horen et al. (1996) studied elastic wave velocities of serpentinized peridotite and reported that the velocity anisotropy decreases with increasing serpentine volume fraction. Their measured velocities indicate that their samples contained Low-T type serpentines (see Section 4.2), although they paid little attention to the mineralogy of the serpentines. Their results can be explained by a random orientation of Low-T type serpentine grains.

\subsection{Velocity difference between High-T and Low-T type serpentinized peridoties}

Mean velocities at $200 \mathrm{MPa}$ are shown in Fig. 8 as a function of density. The mean velocities were calculated from the arithmetic means of three compressional wave velocities and six shear wave velocities. The velocities of serpentinized peridotites reported by previous studies are also shown in Fig. 8. The mineralogy of serpentines is not specified in Kern and Tubia (1993) and Horen et al. (1996). Velocities were measured at room temperature and $200 \mathrm{MPa}$, with the exception of those of Horen et al. (1996) who measured velocities of serpentinites from Xigaze ophiolite (Tibet) at atmospheric pressure. Based on the scarcity of cracks and the small effect of water saturation on velocities, their velocities can be directly compared with velocities measured at $200 \mathrm{MPa}$ (see Fig. 2 in Horen et al., 1996). Dewandel et al. (2003) reported velocities of serpentinized peridotite from Oman ophiolite. Although the density was 


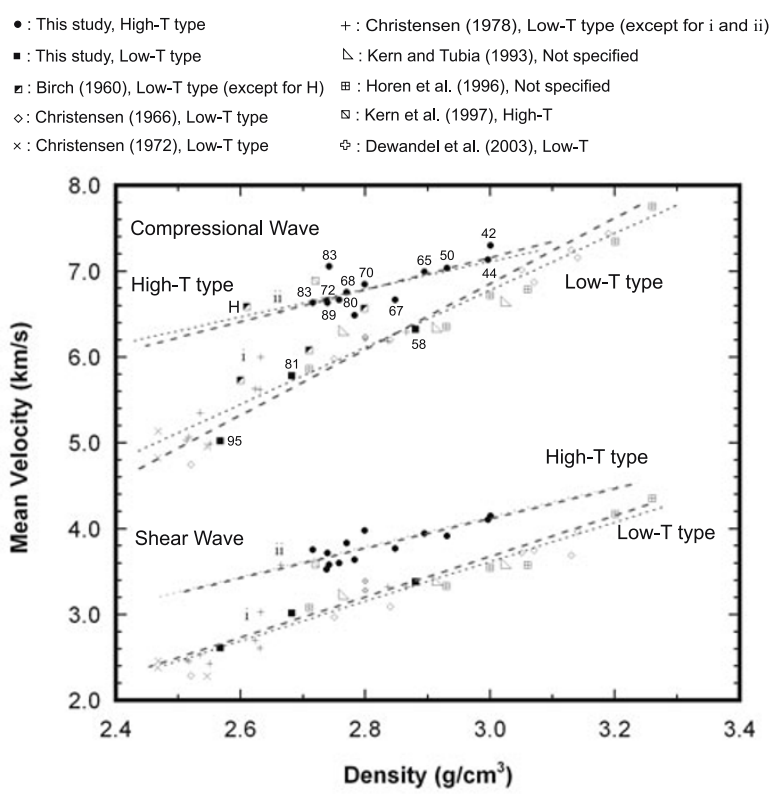

Fig. 8. Mean compressional and shear wave velocities measured at 200 $\mathrm{MPa}$ as a function of the density. Mean velocities measured at $200 \mathrm{MPa}$ in the literature are also shown. The mean velocity is an arithmetic mean of three or six velocities. Alhough Horen et al. (1996) conducted velocity measurements at atmospheric pressure, their velocities appear to suffer little effect from pores. The symbol "i" and "ii" indicate Serpentinite (1) and (2), respectively, from Stonyford, California in Christensen (1978). Dashed lines are obtained only from this study by the least-square method, while thin dotted lines indicate our measurements and those of previous studies.

not provided, the volume fraction of serpentines (lizardite and chrysotile) was reported to be $60 \%$. The density of their specimen was estimated by an empirical relation between the density and the serpentine volume fraction (Fig. 2 in Carlson and Miller, 2003), which is applicable to Low-T type serpentinized peridoties.

High-T type serpentinized peridoties have significantly higher velocities than their Low-T type counterparts. The velocities of compressional and shear waves increase with increasing density. In Fig. 8, the relations between velocity and density are illustrated by dashed lines, and these were obtained from our velocity data by the least-square method. Serpentines are less dense than the major minerals in peridotites, such as olivines and pyroxenes. The density of lizardite is $2.550 \mathrm{~g} / \mathrm{cm}^{3}$, chrysotile, $2.550 \mathrm{~g} / \mathrm{cm}^{3}$, antigorite, $2.600 \mathrm{~g} / \mathrm{cm}^{3}$, forsterite, $3.213 \mathrm{~g} / \mathrm{cm}^{3}$, and enstatite, 3.209 $\mathrm{g} / \mathrm{cm}^{3}$ (Johnson and Olhoeft, 1984). The changes in density are mainly caused by the change in the volume fraction of serpentines. This is roughly supported by the estimated volume fraction of serpentines (numbers (\%) adjacent to data points in Fig. 8). The volume fraction estimated by point counting is more likely to suffer from the influence of heterogeneity in a sample than the density and velocities. This might be a cause of scattering in the relation between the density and serpentine volume fraction. Figure 8 demonstrates that the velocity decreases with increasing volume fraction of serpentines and that antigorite (High-T type serpentine) has higher velocities than lizardite and chrysotile (Low-T type serpentines).

It should be stressed that velocity values shown in Fig. 8 represent an arithmetic mean of three or six velocities. The elastic wave velocity in a real rock varies more or less with its propagating directions. Ideally, the velocity should be averaged over all directions. This averaged value can be equal to the velocity that the rock would show if it were elastically isotropic. If the specimen is nearly isotropic, the arithmetic mean over three or six directions gives a good approximation of the ideal average. However, if a specimen is strongly anisotropic, the arithmetic mean over only three or six directions can depart significantly from the ideal average. Since most of our High-T type samples have strong anisotropy $\left(k_{p}=0.1-0.3\right)$, the scattering of mean velocities, especially for the compressional wave, reflects the influence of anisotropy. However, although velocities are scattered, we can still state that High-T type serpentinized peridotites have a distinctly higher velocity than Low-T types with the same density. The difference in the crystal structure between High-T and Low-T type serpentines can explain the velocity difference.

Christensen (1978) reported the velocities of two antigorite-bearing serpentinites from Stonyford, California. Serpentinite (2) from Stonyford, which is labeled "ii" in Fig. 5, is on the trend of High-T type serpentinized peridotites, while Serpentinite (1), labeled as "i", shows considerably lower velocities compared to the trend of the High-T type. We suggest that the serpentine mineralogy be carefully studied to understand the reason for this low velocity.

Kern and Tubia (1993) measured velocities of serpentinized peridotites from Ronda peridotites (Spain). Although they did not report the mineralogy of the serpentine, their specimens must be Low-T type. Their velocity values are on the trend of the Low-T type (Fig. 8). In Ronda peridotites, extensive serpentinaization is mainly restricted to the uppermost part, where a serpentine-rich layer with a thickness of $10 \mathrm{~m}$ developed during the last stages of emplacement (Kern and Tubia, 1993). This field observation also suggests that the serpentines are Low-T type.

Horen et al. (1996) did not specify serpentine minerals in their study. However, their velocity data are on the trend of the Low-T type; therefore, the serpentine minerals in their specimens must be Low-T type.

\subsection{Applications to seismological observations}

4.3.1 Interpretation based on Poisson's ratio We estimate Poisson's ratio of serpentinized peridotites and compare it with seismological observations. Our measurements were conducted at room temperature under high confining pressures of up to $200 \mathrm{MPa}$. Measured velocities cannot be directly compared with observed seismic velocities in the wedge mantle; instead, they should be extrapolated to higher pressures and temperatures. However, the velocity ratio $V p / V s$ shows only slight pressure and temperature dependence for most rocks (Christensen, 1996). This reflects the fact that compressional and shear wave velocities vary similarly with pressure and temperature. If a medium is elastically isotropic, Poisson's ratio $v$ is related to the velocity ratio as

$$
v=\frac{1}{2}\left[1-\frac{1}{\left(\frac{V_{p}}{V_{s}}\right)^{2}-1}\right]
$$


Table 4. Velocity ratio and Poisson's ratio calculated from linear trends in Fig. 8.

\begin{tabular}{|c|c|c|c|c|c|c|}
\hline $\begin{array}{l}\text { Density } \\
\left(\mathrm{g} / \mathrm{cm}^{3}\right)\end{array}$ & $\begin{array}{l}\text { Serpentine } \\
\text { content }(\%)\end{array}$ & Type & $\begin{array}{c}V p \\
(\mathrm{~km} / \mathrm{s})\end{array}$ & $\begin{array}{c}V s \\
(\mathrm{~km} / \mathrm{s})\end{array}$ & $V p / V s$ & $\begin{array}{l}\text { Poisson's } \\
\text { ratio }\end{array}$ \\
\hline \multirow[t]{2}{*}{2.60} & 90100 & High-T & 6.49 & 3.43 & 1.89 & 0.31 \\
\hline & & Low-T & 5.44 & 2.68 & 2.03 & 0.34 \\
\hline \multirow[t]{2}{*}{2.80} & 7080 & High-T & 6.81 & 3.77 & 1.81 & 0.28 \\
\hline & & Low-T & 6.11 & 3.14 & 1.94 & 0.32 \\
\hline \multirow[t]{2}{*}{3.00} & 4050 & High-T & 7.14 & 4.10 & 1.74 & 0.25 \\
\hline & & Low-T & 6.77 & 3.61 & 1.87 & 0.30 \\
\hline
\end{tabular}

The velocity ratio and Poisson's ratio can be used to estimate the lithology.

Table 4 presents mean velocities ( $V p$ and $V s)$, the velocity ratio $V p / V s$, and Poisson's ratio calculated from velocity-density relationships (thin dotted lines in Fig. 8). The linear relationships between velocity and density were obtained from all data in Fig. 8 by the least-square method. Data from Kern and Tubia (1993) and Horen et al. (1996) were treated as Low-T type and Serpentinite (1) in Christensen (1978) ("i" in Fig. 8) was treated as a Low-T type (see Section 4.2). Poisson's ratio increases with decreasing density in both types of serpentinized peridotites, which implies that Poisson's ratio increases with serpentinization. Poisson's ratio in the High-T type is distinctly lower than in the Low-T type with the same density, which may also reflect the difference in crystal structure between the serpentine minerals. Although Poisson's ratio was estimated from arithmetic means of velocities, our discussion about Poisson's ratio of High-T and Low-T type serpentinized peridotites can be true at least qualitatively.

Kamiya and Kobayashi (2000) determined seismic velocity structure beneath the Kanto district, Central Japan, and found a region of high Poisson's ratio $(0.30 \sim 0.35)$ just above the subducting Philippine Sea slab (depth $=30 \sim 45$ $\mathrm{km})$. They interpreted this high Poisson's ratio region as a serpentinized region. The observed Poisson's ratio can be explained by the existence of Low-T type serpentinized peridotites. However, antigorite is expected to exist in this region based on the estimated temperature of $400-600^{\circ} \mathrm{C}$ (Iwamori, 2000). It may be difficult to explain the observed high Poisson's ratio by the presence of High-T type serpentinized peridotites because Poisson's ratio estimated for the High-T type is at most 0.31 . Other causes, such as the existence of high-pressure fluid in pores (Christensen, 1984), may be required to explain the observed high Poisson's ratio.

Deshon and Schwartz (2004) found a region of $V p / V s \sim 1.85$ in the forearc mantle wedge along the Nicoya Peninsula, Costa Rica, and interpreted it to indicate a serpentinized region. They estimated the degree of serpentinization to be $15-25 \%$ based on the properties of Low-T type serpentinized peridotites (Carlson and Miller, 2003). However, in terms of High-T type serpentinized peridotites, a much higher degree of serpentinization (70$90 \%$ ) is needed to give $V p / V s \sim 1.85$. This implies that the wedge mantle contains more water than they estimated.

We stress once again that High-T type serpentinized peridotites have properties that are distinct from those of Low-T type serpentinized peridotites. When we interpret the high Poisson's ratio in the wedge mantle, we must first evaluate the temperature structure, which mainly depends on the age of the subducting slab. A stable phase of serpentines is determined from the temperature structure and phase relations. Properties of a stable phase will lead to the proper interpretation of a high Poisson's ratio. Our knowledge of the properties of antigorite-bearing rocks is still limited. The precise determination of Poisson's ratio and the pressure and temperature dependence of velocities are required. The velocty measurement in many directions of a rock sample enables us to determine all of the elastic constants (e.g., Sano et al., 1992). The Voigt-Reuss-Hill average of the elastic constants therefore provides the velocity that the sample would have if it were isotropic. Poisson's ratio should be determined from the isotropic velocities.

4.3.2 Implication of velocity anisotropy High-T type serpentinized peridoties with strong foliation will show significant velocity anisotropy at the conditions of high pressure and temperature expected in the wedge mantle, although our measurements are limited to room temperature and lower pressures. Kern et al. (1997) measured the velocities of a strongly foliated serpentinized peridotite with $75 \mathrm{vol} \%$ antigorite at temperatures of $20-700^{\circ} \mathrm{C}$ and 600 $\mathrm{MPa}$. The azimuthal anisotropy of the compressional wave velocity was around $24 \%$ at room temperature and showed only slight temperature dependence (only a few percentages) up to $600^{\circ} \mathrm{C}$, whereas velocities decreased by $0.3-0.4$ $\mathrm{km} / \mathrm{s}$ with increasing temperature.

High-T type serpentine (antigorite) can cause strong velocity anisotropy in the wedge mantle. The velocity anisotropy of antigorite is qualitatively similar to that of such sheet silicates as micas, although quantitative knowledge on the elastic properties of antigorite is still limited. The azimuthal anisotropy of the compressional wave velocity in micas reaches 60\% (Babska and Cara, 1991). On the other hand, the azimuthal anisotropy in a single crystal of olivine, which is the most abundant mineral in the uppermost mantle, is at most 25\% (Kumazawa and Anderson, 1969). The azimuthal anisotropy caused by the alignment of olivine grains should be less than $25 \%$. The alignment of antigorite grains can cause stronger anisotropy than that of olivine grains.

Let us consider a region near the slab-mantle interface in a warm subduction zone. Water released from the subducting slab reacts with the mantle peridotite to produce antigorite. Because the deformation in the mantle is constrained by the subducting slab, foliation planes will be de- 
veloped parallel to the subducting slab in the serpentinized region. The sheet structure of antigorite grains are aligned to cause a significant velocity anisotropy. The compressional wave perpendicular to the subducting slab will have a significantly low velocity $(\sim 6 \mathrm{~km} / \mathrm{s})$. When the serpentinization and the development of foliation proceed sufficiently, a large impedance contrast can develop at the top of a serpentinized region, which is the interface between a mantle peridotite and a serpentinized peridotite. This interface can strongly reflect compressional waves of normal incidence. A serpentinized region should be considered as a possible cause of seismic reflection. Further understanding requires more detailed knowledge of the elastic properties of antigorite at high pressures and temperatures.

\section{Conclusions}

Velocities of compressional and shear waves in serpentinized peridotites were measured at room temperature under a high confining pressure of up to $200 \mathrm{MPa}$. Rock samples were collected from the Hida outer belt, Central Japan, and classified into High-T and Low-T types based on the mineralogy of the serpentine.

In both types, velocities of compressional and shear waves decrease with decreasing density, implying that velocities decrease with serpentinization. The High-T type has a distinctly higher velocity than the Low-T type with the same density. High-T type samples with strong foliation show significant velocity anisotropy, with the azimuthal anisotropy of the compressional wave velocity reaching $30 \%$. Antigorite grains are aligned parallel or subparallel to the foliation planes. The higher velocity and significant anisotropy can be understood based on the structure of antigorite, in which 1:1 layers are stacked and bonded by Si-O bonding.

Poisson's ratio was estimated from our measurements and previous studies. Poisson's ratio increases with serpentinization in both types of serpentinized peridotites, with the High-T type showing a lower value than the Low-T type with the same density. A higher degree of serpentinization is required in the High-T type to give a certain value of Poisson's ratio than in the Low-T type. This implies that a higher water content is required in the High-T type. In order to interpret an observed high Poisson's ratio region, it is essential to use the properties of an appropriate type of serpentinized peridotietes. The temperature structure and phase relations will tell us which type is appropriate for the region.

A strong foliation might be developed in a serpentinized region near the slab-mantle interface. The top of this region, which is the interface between a mantle peridotite and a serpentinized peridotite, can work as a seismic reflector.

Acknowledgments. We would like to thank Y. Kobayashi and I. Kawasaki for motivating us to do this work. S. Arai, Y. Ishida, O. Ujike, M. Shimizu, and S. Ohtoh are also thanked for their help in sampling, processing and analyzing of specimens. H. Kern and an anonymous reviewer are thanked for their constructive comments and suggestions. This work was partly supported by Cooperative Research Program (15G-03) of Disaster Prevention Research Institute, Kyoto University and Cooperative Research Pro- gram (2004-A-16) of Earthquake Research Institute, University of Tokyo.

\section{References}

Babuska, V. and M. Cara, Seismic Anisotropy in the Earth, Kluwer Academic Publishers, 217 pp., 1991.

Birch, F., The velocity of compressional waves in rocks to 10 kilobars, Part 1, J. Geophys. Res., 65, 1083-1102, 1960.

Birch, F., The velocity of compressional waves in rocks to 10 kilobars, Part 2, J. Geophys. Res., 66, 2199-2224, 1961.

Bostock, M. G., R. D. Hyndman, S. Rondenay, and S. M. Peacock, An inverted continental Moho and serpentinization of the forearc mantle, Nature, 417, 536-538, 2000.

Carlson, R. L. and D. J. Miller, Mantle wedge water contents estimated from seismic velocities in partially serpentinized peridotites, Geophys. Res. Lett., 30, 1250-1253, 2003.

Chihara, K., M. Komatsu, T. Uemura, Y. Hasegawa, S. Shiraishi, T. Yoshimura, and M. Nakamizu, Geology and tectonics of the Omi-Renge and Joetsu tectonic belts, Sci. Rept. Niigata Univ., Ser. E, 5, 1-61, 1979.

Christensen, N. I., Elasticity of ultrabasic rocks, J. Geophys. Res., 71, 5921-5931, 1966.

Christensen, N. I., The abundance of serpentinites in the oceanic crust, $J$. Geol., 80, 709-719, 1972.

Christensen, N. I., Ophiolites, seismic velocities and oceanic crustal structure, Tectonophys., 47, 131-157, 1978.

Christensen, N. I., Pore pressure and oceanic crustal seismic structure, Geophys. J. R. astr. Soc., 79, 411-423, 1984.

Christensen, N. I., Poisson's ratio and crustal seismology, J. Geophys. Res., 101, 3139-3156, 1996.

DeShon, H. and S. Y. Schwartz, Evidence for serpentinization of the forearc mantle wedge along the Nicoya Peninsula, Costa Rica, Geophys. Res. Lett., 31, L21611, doi:10.1029/2004GL021179, 2004.

Dewandel, B., F. Boudier, H. Kern, W. Warsi, and D. Mainprice, Seismic wave velocity and anisotropy of serpentinized peridotite in the Oman ophiolite, Tectonophys., 370, 77-94, 2003.

Evans, B. W., W. Johannes, H. Oterdoom, and V. Trommsdorf, Stability of chrysotile and antigorite in the serpentine multisystem, Schweiz Mineral. Petrogr. Mitt., 56, 79-93, 1976.

Graeber, F. M. and G. Asch, Three-dimensional models of $P$ wave velocity and P-to-S ratio in the southern central Andes by simultaneous inversion of local earthquake data, J. Geophys. Res., 104, 20237-20256, 1999.

Horen, H., M. Zamora, and G. Dubuisson, Seismic wave velocities and anisotropy in serpentinized peridotites from Xigaze ophiolite: Abundance of serpentine in slow spreading ridge, Geophys. Res. Lett., 23, 9-12, 1996.

Iwamori, H., Transportation of $\mathrm{H}_{2} \mathrm{O}$ and melting in subduction zones, Earth Planet. Sci. Lett., 160, 65-80, 1998.

Iwamori, H., Deep subduction of $\mathrm{H}_{2} \mathrm{O}$ and deflection of volcanic chain towards backarc near triple junction due to lower temperature, Earth Planet. Sci. Lett., 181, 41-46, 2000.

Johnson, G. R. and G. R. Olhoeft, Densities of rocks and minerals, in Practical Handbook of Physical Properties of Rocks and Minerals vol. III, edited by R. S. Carmichael, 1-38, 1984.

Kamiya, S. and Y. Kobayashi, Seismological evidence for the existence of serpentinized wedge mantle, Geophys. Res. Lett., 27, 819-822, 2000.

Kern, H. B. and J. M. Tubia, Pressure and temperature dependence of Pand S-wave velocities, seismic anisotropy and density of sheared rocks from Sierra Alpujata massif (Ronda peridotites, Southern Spain), Earth Planet. Sci. Lett., 119, 191-205, 1993.

Kern, H., B. Liu, and T. Popp, Relationship between anisotropy of P and $\mathrm{S}$ wave velocities and anisotropy attenuation in serpentinite and amphibolite, J. Geophys. Res., 102, 3051-3065, 1997.

Kumazawa, M. and O. L. Anderson, Elastic moduli, pressure derivatives, and temperature derivatives of single-crystal olivine and single-crystal forsterite, J. Geophys. Res., 74, 5961-5972, 1969.

Nesse, W. D., Introduction to Optical Mineralogy, 3rd ed., Oxford University Press, 348 pp., 2004.

O'Connell, R. J. and B. Budiansky, Seismic velocities in dry and saturated cracked solids, J. Geophys. Res., 79, 5412-5426, 1974.

O'Hanley, D. S., A chemographic analysis of magnesian serpentinites using dual networks, Can. Mineral., 25, 121-133, 1987.

O'Hanley, D. S., Serpentinites, Records of Tectonic and Petrological History, Oxford University Press, 277 pp., 1996.

Peacock, S. M. and R. D. Hyndman, Hydrous minerals in the mantle wedge and the maximum depth of subduction thrust earthquakes, Geophys. 
Res. Lett., 26, 2517-2520, 1999.

Peacock, S. M. and K. Wang, Seismic consequences of warm versus cool subduction metamorphism: examples from Southwest and Northwest Japan, Science, 286, 937-939, 1999.

Sanford, R. F., Mineralogical and chemical effects of hydration reactions and applications to serpentinizations, Am. Mineral., 66, 290-297, 1981.

Sano, O., Y. Kudo, and Y. Mizuta, Experimental determination of elastic constants of Ohshima granite, Barrea granite, and Chelmsford granite, J. Geophys. Res., 97, 3367-3379, 1992.
Ulmer, P. and V. Trommsdorff, Serpentinite stability to mantle depths and subduction-related magmatism, Science, 268, 858-861, 1995.

Wicks, F. J. and D. S. O'Hanley, Serpentine minerals: structures and petrology, in Reviews in Mineralogy, vol. 19: Hydrous Phyllosilicates, edited by S. W. Bailey, 91-167, 1988.

T. Watanabe (e-mail: twatnabe@sci.u-toyama.ac.jp), H. Kasami, and S. Ohshima 